VILLELA JCB; BARBIERI RL; CASTRO CM; NEITZKE RS; VASCONCELOS CS; CARBONARI T; MISTURA CC; PRIORI D. 2014. Caracterização molecular de pimentas crioulas (Capsicum baccatum) com marcadores microssatélites. Horticultura Brasileira 32: 131-137.

\title{
Caracterização molecular de variedades crioulas de pimentas (Capsicum baccatum) com marcadores microssatélites
}

\author{
Juliana CB Villela ${ }^{1}$; Rosa L Barbieri ${ }^{1}$; Caroline M Castro ${ }^{1}$; Raquel S Neitzke ${ }^{2}$; Carla S Vasconcelos ${ }^{2}$; Taíse \\ Carbonari² $^{2}$ Claudete C Mistura ${ }^{2}$; Daniela Priori ${ }^{2}$ \\ 1Embrapa Clima Temperado, C. Postal 403, 96001-970 Pelotas-RS; jcbrancov@gmail.com; lia.barbieri@embrapa.br; caroline.castro@ \\ embrapa.br; ${ }^{2}$ UFPel, C. Postal 354, 96010-900 Pelotas-RS; raquelsilviana@gmail.com; carla_sigales@hotmail.com; taise.carbonari@ \\ gmail.com; claudetec.mistura@gmail.com; dani_priori@yahoo.com.br
}

\section{RESUMO}

Atualmente, muitas variedades crioulas de Capsicum baccatum são cultivadas pelos agricultores no Brasil. Essas populações são fontes de genes para tolerância ou resistência aos estresses bióticos e abióticos. Porém, grande parte dessas variedades está sendo perdida devido à erosão genética causada pela substituição de cultivares. A fim de conservar e caracterizar as variedades crioulas, a Embrapa Clima Temperado mantém, desde 2002, um Banco Ativo de Germoplasma de Capsicum. Com o objetivo de caracterizar variedades crioulas de C. baccatum com marcadores moleculares de microssatélites, foram analisados vinte acessos que integram o acervo do Banco Ativo de Germoplasma de Capsicum da Embrapa Clima Temperado. O DNA foi extraído individualmente das folhas jovens de cinco plantas de cada acesso. Foram analisados oito loci de microssatélites, identificando um total de 43 alelos. Todos os loci analisados foram polimórficos. A análise molecular da variância mostrou uma diversidade genética de $51,37 \%$ entre acessos e $48,63 \%$ dentro dos acessos, o que evidenciou a existência de segregação em diversas variedades crioulas de pimentas avaliadas. Os grupos obtidos pela análise de agrupamento não tiveram relação com as características morfológicas dos frutos. A maior proporção da variabilidade genética encontra-se entre as diferentes variedades crioulas, embora também exista variabilidade genética dentro de cada acesso.

Palavras-chave: Solanaceae, recursos genéticos, marcadores moleculares, distância genética.

\begin{abstract}
Molecular characterization of landraces of peppers (Capsicum baccatum) with SSR markers

Currently, many landraces of C. baccatum are grown by farmers in Brazil. These populations are sources of genes for resistance or tolerance to abiotic and biotic stresses. However, most of these landraces are being lost due to genetic erosion caused by substitution of cultivars. In order to characterize and conserve landraces, since 2002 Embrapa Temperate Agriculture maintains an Active Germplasm Bank of Capsicum. This work has the objective to characterize landraces of $C$. baccatum using microsatellite markers. 20 accessions from the Active Germplasm Bank of Capsicum of Embrapa Temperate Agriculture were analyzed. DNA was extracted individually from young leaves collected from five plants of each accession. Eight microsatellite loci were analyzed. All loci were polymorphic. Molecular analysis of variance showed values of genetic diversity as $51.37 \%$ among accessions and $48.63 \%$ within the accessions. This fact showed the existence of segregation in many of these pepper landraces. The groups obtained by cluster analysis did not correlate with morphological fruit traits. Most of the genetic variability is found among different landraces, although there is also genetic variability within each accession.
\end{abstract}

Keywords: Solanaceae, genetic resources, molecular markers, genetic distance.

(Recebido para publicação em 1 de julho de 2013; aceito em 25 de março de 2014) (Received on July 1, 2013; accepted on March 25, 2014)

$\mathrm{A}$ s pimentas do gênero Capsicum (Solanaceae) são representadas por mais de 30 espécies, classificadas em domesticadas, semidomesticadas e silvestres (Pozzobon et al., 2006; Moscone et al., 2007; Barboza et al., 2011). Cinco destas espécies são domesticadas, sendo cultivadas em uma grande variedade de tipos, tamanhos, cores, sabores e pungências (Neitzke et al., 2010).

Muito antes da chegada de Cristóvão Colombo às Américas, as pimentas do gênero Capsicum eram amplamente cultivadas neste continente. Registros arqueológicos datados de seis mil anos indicam que o cultivo de milho e pimenta ocorria consorciado, formando um complexo alimentar muito antigo e amplamente disseminado desde o sul dos Estados Unidos até a região central da Argentina e do Chile, antecedendo inclusive o desenvolvimento da cerâmica em algumas regiões (Perry et al., 2007). $\mathrm{Na}$ época da chegada dos conquistadores europeus ao Novo Mundo, C. baccatum,
C. chinense e $C$. frutescens faziam parte dos cultivos indígenas no atual território brasileiro, enquanto que $C$. annuит e $C$. pubescens não eram cultivadas no Brasil (Andrews, 1995).

Capsicum baccatum é bastante cultivada no país, especialmente na região Sul (Neitzke, 2012). A pimenta dedo-de-moça e a pimenta cambuci são exemplos desta espécie. A forma domesticada de $C$. baccatum é classificada botanicamente como $C$. baccatum var. pendulum, e a silvestre como $C$. 
baccatum var. baccatum. A forma silvestre está restrita à Bolívia e áreas circundantes, e é provável que seu cultivo tenha iniciado nesta região (Heiser, 1995). Conforme Clement et al. (2010), o centro de origem de $C$. baccatum se localiza nas partes mais baixas dos vales andinos da Bolívia. Esta espécie é facilmente identificada pela presença de manchas amareladas ou marrons na corola, com estames amarelos.

Atualmente, muitas variedades locais de $C$. baccatum são cultivadas pelos agricultores no Brasil, sendo denominadas também de variedades crioulas. Essas populações são fontes de genes para tolerância ou resistência aos estresses bióticos e abióticos. Porém, grande parte dessas variedades está sendo perdida devido à erosão genética causada pela substituição de cultivos. A fim de conservar e caracterizar as variedades crioulas, a Embrapa Clima Temperado mantém, desde 2002, um Banco Ativo de Germoplasma (BAG) de Capsicum.

A caracterização das coleções de germoplasma e a determinação da distância genética entre os acessos tem grande importância na identificação e seleção de genótipos de interesse aos programas de melhoramento genético (Sudré et al., 2010). A variação entre e dentro dos acessos pode ser analisada por métodos específicos ou combinações de métodos, que incluem variáveis quantitativas e qualitativas (Barbé et al., 2010). Marcadores moleculares microssatélites ou SSR (Single sequence repeats) têm sido usados como uma eficiente ferramenta para a caracterização de acessos em bancos de germoplasma (Santos et al., 2011; Oliveira et al., 2012; Olvera et al., 2012).

Neste contexto, o presente trabalho teve como objetivo caracterizar com marcadores moleculares de microssatélites acessos de variedades crioulas de C. baccatum do Banco Ativo de Germoplasma de Capsicum da Embrapa Clima Temperado.

\section{MATERIAL E MÉTODOS}

Foram analisados vinte acessos de variedades crioulas de Capsicum baccatum procedentes de diferentes regiões do Brasil (Tabela 1), os quais fazem parte do acervo do Banco Ativo de Germoplasma de Capsicum da Embrapa Clima Temperado.

As plantas foram cultivadas em casa de vegetação, em bandejas de isopor preenchidas com substrato (Turfa Fértil $^{\circledR}$ ). Em laboratório da Embrapa Clima Temperado o DNA foi extraído individualmente das folhas jovens coletadas de cinco plantas de cada acesso. A extração de DNA foi realizada de acordo com o protocolo descrito por Ferreira \& Grattapaglia (1998). Os testes de qualidade e a quantificação do DNA foram feitos em gel de agarose $1 \%$, corado com Gel Red (1:500 $\mu \mathrm{L})$. O DNA foi quantificado no gel por comparação com os padrões de bandas do marcador $\lambda D N A$ HindIII (Invitrogen). Após a quantificação, o DNA foi diluído em TE para uma concentração de $50 \mathrm{ng} / \mu \mathrm{L}$.

A caracterização molecular foi realizada com oito loci de microssatélites descritos por Nagy et al. (1998) e Lee et al. (2004) (Tabela 2). As reações de amplificação de microssatélites (PCR-SSR) foram realizadas em volume final de reação de $20 \mu \mathrm{L}$, contendo $2,0 \mu \mathrm{L}$ de 10x PCR Buffer, 1,0 $\mu \mathrm{L}$ de $\mathrm{MgCl}_{2}$ (50 mM), 1,6 $\mu \mathrm{L}$ de DNTPs $(12,5$ $\mathrm{mM}), 1,3 \mu \mathrm{L}$ de BSA $(10 \mathrm{mg} / \mu \mathrm{L}), 1,0$ $\mu \mathrm{L}$ de cada primer $(10 \mu \mathrm{M}), 0,2 \mu \mathrm{L}$ de Taq DNA Polimerase $(5 \mathrm{u} / \mu \mathrm{L})$ e $1,0 \mu \mathrm{L}$ de DNA (50ng/ $\mu \mathrm{L})$. As amplificações foram realizadas em termociclador Applied BioSystems GeneAmp PCR System 9700, programado para uma etapa inicial de desnaturação do DNA a $94^{\circ} \mathrm{C}$ por 4 min e $40 \mathrm{~s}$, seguido de 30 ciclos de $15 \mathrm{~s}$ a $94^{\circ} \mathrm{C}$ (desnaturação), $10 \mathrm{~s}$ a $60^{\circ} \mathrm{C}$ (anelamento) e $15 \mathrm{~s} \mathrm{a} 72^{\circ} \mathrm{C}$. Por fim, uma etapa de $5 \mathrm{~min}$ a $72^{\circ} \mathrm{C}$. As temperaturas de anelamento variaram de 50 a $60^{\circ} \mathrm{C}$, conforme a temperatura do primer utilizado (Tabela 2). Os fragmentos amplificados foram separados por eletroforese horizontal em gel de agarose (Invitrogen) 3,5\%, corado com Gel Red $(1: 500 \mu \mathrm{L})$ e tampão TBE $1 \mathrm{X}$ (Tris-Borato $90 \mathrm{mM}$, EDTA $2 \mathrm{mM}$ ). O marcador $1 \mathrm{~Kb}$ Plus DNA ladder (Invitrogen) foi utilizado como referência para estimar o tamanho dos fragmentos amplificados. Em seguida o gel foi visualizado em luz ultravioleta (UV) e documentado em fotodocumentador
(Kodak Gel Logic 212 Imaging System, Molecular Imaging System Carestream Health, Inc., Rochester, NY, EUA). Os alelos amplificados foram identificados de acordo com o peso molecular das bandas geradas e uma matriz multialélica foi construída para cada locus analisado.

A partir da matriz gerada com base na leitura dos géis de dados codominantes, foi estimada a distância euclidiana entre os indivíduos. Com base no quadrado da distância euclidiana foram calculadas as estimativas da variabilidade genética entre e dentro dos 20 acessos de variedades crioulas de C. baccatum por meio da análise molecular da variância AMOVA (analysis of molecular variance) utilizando o programa computacional Genes (Cruz, 2006).

A AMOVA permite calcular o valor $F_{s t}$ equivalente à proporção da variação total compartilhada entre dois acessos. Para testar a significância dos resultados da AMOVA foi utilizado o método não-paramétrico de permutações (Excoffier et al., 1992).

A partir da matriz multialélica para cada locus analisado, foi também estimado: i) o conteúdo de informação de polimorfismo (PIC) de cada locus por meio da equação:

$$
P I C=1-\sum_{i=l}^{k} p i^{2}
$$

onde $p_{i}$ é a frequência ao quadrado do alelo $i$; ii) a distância genética entre os acessos com base na distância de Rogers Modificado (Wright, 1978), utilizando o software NTSYS-PC, versão 2.1 (Rohlf, 2000), conforme a equação: $D W=\frac{1}{\sqrt{2 m}} \sqrt{\sum_{i=1}^{m} \sum_{j=1}^{n j}\left(P_{i j}\right.}-Q_{i}$

onde $p_{i j} \mathrm{e} q_{i j}$ correspondem às frequências do alelo $j$ no locus $i$ nos dois genótipos em consideração, $n_{i}$ é o número de alelos do locus $i$, e $m$ se refere ao número total de loci analisados.

A matriz de distância genética foi utilizada para a construção do dendrograma, por meio do método de agrupamento da distância média UPGMA (unweighted pair group method using arithmetic average). $\mathrm{O}$ ajuste entre a matriz de distância genética e o dendrograma foi estimado pelo coeficiente de correlação cofenética (r), conforme 
Sokal \& Rohlf (1962), utilizando o programa computacional NTSYS-PC (Rohlf, 2000). Esse coeficiente traduz a relação momento-produto, calculado entre os elementos da matriz original e os da matriz cofenética, resultante da simplificação proporcionada pelo método de agrupamento, depois da construção do dendrograma. Valores de (r) acima de 0,80 indicam boa representatividade entre as distâncias (Bussad et al., 1990).

\section{RESULTADOS E DISCUSSÃO}

$\mathrm{Na}$ análise dos 20 acessos de variedades crioulas de pimentas com oito loci microssatélites foram identificados 43 alelos. A média do número de alelos por locus foi de cinco, variando de três a oito. O locus $\mathrm{Ng} 12$ apresentou a maior diversidade alélica, oito alelos, seguido de $\mathrm{Ng} 08, \mathrm{Bd} 70$, e $\mathrm{Ng} 17$ que apresentaram seis alelos. As frequências alélicas variaram de 0,03 a 0,63 com média de 0,20 . Dos 43 alelos, oito foram identificados como raros, com frequência alélica inferior a 0,05 (Moura et al., 2009). Os loci Bd70, NG12 e Bd33_A apresentaram mais de um alelo raro por

Tabela 1. Acessos de variedades crioulas de Capsicum baccatum analisadas (accessions of landraces of Capsicum baccatum analyzed). Pelotas, Embrapa Clima Temperado, 2012.

\begin{tabular}{|c|c|c|c|}
\hline Acesso & Nome popular & Características dos frutos & Procedência \\
\hline P8 & pimenta & $\begin{array}{l}\text { pungentes, alongados; branco amarelados, amarelo esverdeados, } \\
\text { alaranjados quando imaturos e vermelhos quando maduros }\end{array}$ & Renascença-PR \\
\hline P11 & pimenta & $\begin{array}{l}\text { pungentes, alongados, verdes quando imaturos e vermelho-escuros } \\
\text { quando maduros }\end{array}$ & Farroupilha-RS \\
\hline P14 & $\begin{array}{l}\text { pimentão chapéu- } \\
\text { de-padre }\end{array}$ & $\begin{array}{l}\text { sem pungência, campanulados, verdes quando imaturos e vermelho- } \\
\text { escuros quando maduros }\end{array}$ & Renascença-PR \\
\hline P25 & $\begin{array}{l}\text { pimenta } \\
\text { ornamental }\end{array}$ & $\begin{array}{l}\text { pungentes, triangulares; branco-amarelados, alaranjados e violeta, } \\
\text { quando imaturos e vermelho-escuros quando maduros }\end{array}$ & Pelotas-RS \\
\hline $\mathrm{P} 27$ & pimentão amarelo & $\begin{array}{l}\text { sem pungência, campanulados, verdes quando imaturos e amarelos } \\
\text { quando maduros }\end{array}$ & Renascença-PR \\
\hline P28 & $\begin{array}{l}\text { pimenta } \\
\text { ornamental }\end{array}$ & $\begin{array}{l}\text { pungentes, triangulares, verde quando imaturos e vermelho quando } \\
\text { maduros }\end{array}$ & Renascença-PR \\
\hline P59 & pimenta forte & $\begin{array}{l}\text { pungentes, triangulares, verde amarelados quando imaturos e } \\
\text { vermelho claros quando maduros }\end{array}$ & Cristal-RS \\
\hline P71 & $\begin{array}{l}\text { pimenta dedo-de- } \\
\text { moca }\end{array}$ & $\begin{array}{l}\text { pungentes, alongados, verdes quando imaturos e vermelho-escuros } \\
\text { quando maduros }\end{array}$ & Pelotas-RS \\
\hline Р 179 & pimentão & $\begin{array}{l}\text { sem pungência, alongados, verdes quando imaturos e vermelhos } \\
\text { quando maduros }\end{array}$ & Rio Grande-RS \\
\hline Р 207 & pimenta cumari & $\begin{array}{l}\text { pungentes, ovais, verdes quando imaturos e vermelhos quando } \\
\text { maduros }\end{array}$ & Pelotas-RS \\
\hline P 235 & $\begin{array}{l}\text { pimentinha dedo- } \\
\text { de-moça }\end{array}$ & $\begin{array}{l}\text { pungentes, alongados, verdes quando imaturos e vermelhos quando } \\
\text { maduros }\end{array}$ & Belém-PA \\
\hline P 239 & pimenta & $\begin{array}{l}\text { pungentes, alongados, verdes quando imaturos e vermelhos quando } \\
\text { maduros }\end{array}$ & Pelotas-RS \\
\hline P 241 & pimenta & $\begin{array}{l}\text { pungentes, alongados, verdes quando imaturos e vermelhos quando } \\
\text { maduros }\end{array}$ & Correntes-PI \\
\hline P265 & pimenta cumari & $\begin{array}{l}\text { pungentes, arredondados, verdes quando imaturos e vermelhos } \\
\text { quando maduros }\end{array}$ & $\begin{array}{l}\text { Vargem Gde. do } \\
\text { Sul-SP }\end{array}$ \\
\hline P276 & pimenta & $\begin{array}{l}\text { pungentes, alongados, verdes quando imaturos e vermelhos quando } \\
\text { maduros }\end{array}$ & Turuçu-RS \\
\hline P280 & pimenta & $\begin{array}{l}\text { pungentes, alongados, verdes quando imaturos e vermelho escuros } \\
\text { quando maduros }\end{array}$ & Pelotas-RS \\
\hline P283 & pimenta & $\begin{array}{l}\text { pungentes, alongados, verdes quando imaturos e vermelhos quando } \\
\text { maduros }\end{array}$ & $\begin{array}{l}\text { Cachoeira do } \\
\text { Sul-RS }\end{array}$ \\
\hline P284 & pimenta & $\begin{array}{l}\text { pungentes, retangulares, verdes quando imaturos e vermelhos } \\
\text { quando maduros }\end{array}$ & $\begin{array}{l}\text { Cachoeira do } \\
\text { Sul-RS }\end{array}$ \\
\hline P285 & pimenta & pungentes & $\begin{array}{l}\text { Cachoeira do } \\
\text { Sul-RS }\end{array}$ \\
\hline P286 & pimenta & $\begin{array}{l}\text { pungentes, alongados, verdes quando imaturos e vermelhos quando } \\
\text { maduros }\end{array}$ & $\begin{array}{l}\text { Cachoeira do } \\
\text { Sul-RS }\end{array}$ \\
\hline
\end{tabular}


Tabela 2. Marcadores microssatélites utilizados na caracterização de 20 acessos de variedades crioulas de pimentas Capsicum baccatum, números de alelos obtidos por locus, tamanhos de alelos identificados, amplitude das frequências alélicas e conteúdo de informação do polimorfismo (PIC) [microsatellite markers used to characterization of 20 accessions of landraces of peppers Capsicum baccatum, number of alleles obtained per locus, sizes of alleles identified, range of allele frequencies and polymorphism information content (PIC)]. Pelotas, Embrapa Clima Temperado, 2012.

\begin{tabular}{|c|c|c|c|c|c|c|c|c|}
\hline \multirow{2}{*}{$S S R$} & \multirow{2}{*}{ Locus } & \multicolumn{2}{|c|}{ Primer } & \multirow{2}{*}{$\begin{array}{c}\text { Temp. de } \\
\text { anelamento } \\
\left({ }^{\circ} \mathrm{C}\right)\end{array}$} & \multirow{2}{*}{$\begin{array}{c}\text { Alelos } \\
\left(\mathbf{n}^{0}\right)\end{array}$} & \multirow{2}{*}{$\begin{array}{c}\text { Tamanhos dos } \\
\text { alelos (pb) }\end{array}$} & \multirow{2}{*}{$\begin{array}{c}\text { Frequência } \\
\text { alélica }\end{array}$} & \multirow{2}{*}{ PIC } \\
\hline & & Forward & Reverse & & & & & \\
\hline $\mathrm{Ng8}$ & CA516044 & atcttcttctcatttctccettc & tgctcagcattaacgacgtc & $55,35^{\circ} \mathrm{C}$ & 6 & $\begin{array}{l}182 ; 192 ; 198 ; \\
211 ; 224 ; 250\end{array}$ & $0,30-0,35$ & 1 \\
\hline Ng12 & $B M 064867$ & tctgggaattttggaactgc & tccagttttgatcatctccaac & $55,29^{\circ} \mathrm{C}$ & 8 & $\begin{array}{c}146 ; 157 ; 170 \\
182 ; 202 ; 217 \\
248 ; 255\end{array}$ & $0,01-0,10$ & 0,75 \\
\hline $\mathrm{Ng} 17$ & GPMS 93 & atccttggegtattttgcac & ttcactttgcacacaggctt & $55,35^{\circ} \mathrm{C}$ & 6 & $\begin{array}{l}241 ; 251 ; 274 ; \\
287 ; 317 ; 422\end{array}$ & $0,003-0,38$ & 0,57 \\
\hline $\mathrm{Ng} 18$ & CA517699 & acgccaagaaaatcatctcc & ccattgctgaagaaaatggg & $55,29^{\circ} \mathrm{C}$ & 3 & $160 ; 171 ; 179$ & $0,16-0,46$ & 0,64 \\
\hline $\mathrm{Bd} 12$ & Hpms 1-139 & ccaacagtaggacccgaaaatcc & atgaaggctactgctgcgatcc & $58,29^{\circ} \mathrm{C}$ & 4 & $\begin{array}{c}209 ; 224 ; 256 \\
308\end{array}$ & $0,006-0,19$ & 0,64 \\
\hline Bd17 & Hpms1-165 & ggctatttccgacaaaccctcag & ccattggtgttttcactgttgtg & $54,35^{\circ} \mathrm{C}$ & 3 & $204 ; 226 ; 238$ & $0,14-0,63$ & 0,54 \\
\hline $\mathrm{Bd} 33 / \mathrm{A}$ & Hpms2-23 & ccctcggctcaggataaatacc & ccccagactcccactttgtg & $57,35^{\circ} \mathrm{C}$ & 4 & $\begin{array}{c}207 ; 232 ; 246 ; \\
252\end{array}$ & $0,04-0,51$ & 0,61 \\
\hline $\mathrm{Bd} 33 / \mathrm{B}$ & Hpms2-23 & ccctcggctcaggataaatacc & ccccagactcccactttgtg & $57,35^{\circ} \mathrm{C}$ & 3 & $115 ; 123 ; 141$ & $0,004-0,36$ & 0,55 \\
\hline $\mathrm{Bd} 70$ & CM0005 & catgaccaccatgaggata & gatagccacgagcatagtatt & $54,29^{\circ} \mathrm{C}$ & 6 & $\begin{array}{l}149 ; 151 ; 161 ; \\
178 ; 187 ; 194\end{array}$ & $0,005-0,45$ & 0,68 \\
\hline
\end{tabular}

\section{locus (Tabela 2).}

O conteúdo de informação polimórfica (PIC) variou de 0,54 para o locus Bd17 a 1,00 para o locus Ng08 (Tabela 3). De acordo com Xie et al. (2010), o polimorfismo dos loci pode ser considerado alto $(\mathrm{PIC}>0,5)$, médio ( $\mathrm{PIC}$ entre $0,5$ e 0,25 ) ou baixo (PIC $<0,25)$. Assim sendo, para os loci analisados no presente trabalho, o PIC observado é alto. Segundo Weir (1996), o conhecimento do conteúdo de informação do polimorfismo é importante, pois fornece uma estimativa do poder discriminatório de um locus. Valores de PIC, entre 0,72 a 0,26 foram relatados por Hanacek et al. (2009) e valores entre 0,66 a 0,27 foram encontrados por Patel et al. (2011) em Capsicum annuum.

Para C. baccatum são escassas as informações referentes à caracterização molecular com marcadores microssatélites. Assim sendo, com base nos PICs dos resultados obtidos neste trabalho, os oito loci analisados apresentaram alto poder discriminatório, sendo os mesmos reco- mendados para estudos de diversidade genética nesta espécie.

Pela AMOVA, os valores da variância molecular considerando os 20 acessos de variedades crioulas de $C$. baccatum apresentaram efeito significativo $(\mathrm{p}<0.01)$ tanto entre como dentro dos acessos.

Foi verificado um padrão semelhante para a distribuição de diversidade genética, 51,37\% entre acessos e 48,63\% dentro de cada acesso. Estes resultados foram semelhantes aos obtidos em populações de $C$. annuum utilizando marcadores moleculares RAPD (random amplified polymorphic DNA) por Oyama et al. (2006). Este fato evidenciou a existência de segregação dentro destas variedades crioulas. A falta de uniformidade genética dentro de variedades crioulas de Capsicum baccatum também foi relatada por Neitzke (2012) após observar variabilidade genética na arquitetura de planta e morfologia de fruto em lavouras de pimenta dedo-de-moça em Turuçu-RS. Verificou-se que, apesar da maioria das plantas produzirem frutos vermelhos, alongados e com superfície lisa, na mesma lavoura também havia, em menor proporção, plantas com frutos amarelos e alaranjados; com formatos arredondados, triangulares, campanulados e retangulares; e com superfície variando de lisa a rugosa. A variabilidade genética observada foi atribuída a dois fatores: ao tipo de seleção realizada pelos produtores e ao sistema de fecundação das plantas. Cada agricultor utilizava um critério próprio para a obtenção das sementes utilizadas na implantação da lavoura para o próximo cultivo. Alguns selecionavam frutos que consideravam superiores, dentre as plantas mais vigorosas e produtivas, enquanto outros retiravam as sementes aleatoriamente de frutos moídos e desidratados, prontos para comercialização. Quanto ao sistema de fecundação das plantas, as pimentas domesticadas do gênero Capsicum são espécies de autofecundação, mas pode ocorrer polinização cruzada dependendo 
Tabela 3. Análise comparativa $2 \times 2$ entre acessos de variedades crioulas de Capsicum baccatum pela AMOVA. A porcentagem da variação molecular total existente entre os acessos $\left(F_{s t}\right)$ é a medida da distância genética entre os acessos [comparative analysis $2 \times 2$ among accessions of landraces of Capsicum baccatum by AMOVA. The percentage of total molecular variation among the accessions (Fst) is a measure of genetic distance between accessions]. Pelotas, Embrapa Clima Temperado, 2012.

\begin{tabular}{|c|c|c|c|c|c|c|c|c|c|c|}
\hline Acessos & P08 & P11 & P14 & P25 & P27 & P28 & P59 & P71 & P179 & P207 \\
\hline P08 & - & $54,19 * *$ & $64,24 * *$ & $53,18 * *$ & $17,44^{\mathrm{ns}}$ & $35,52 *$ & $68,25 * *$ & $31,15^{* *}$ & $30,54 * *$ & $51,55^{* *}$ \\
\hline P11 & & - & $70,98 * *$ & $60,68 * *$ & $70,00 * *$ & $71,28 * *$ & $56,85 * *$ & $69,64 * *$ & $73,03 * *$ & $64,04 * *$ \\
\hline P14 & & & - & $36,52 * *$ & $74,75 * *$ & $68,88 * *$ & $50,61 * *$ & $71,04 * *$ & $74,90 * *$ & $49,86 * *$ \\
\hline P25 & & & & - & $65,46 * *$ & $57,72 * *$ & $46,28 * *$ & $61,69 * *$ & $64,77 * *$ & $44,22 * *$ \\
\hline P27 & & & & & - & $47,40 * *$ & $66,39 * *$ & $43,75^{* *}$ & $47,29 * *$ & $63,88 * *$ \\
\hline P28 & & & & & & - & $68,25 * *$ & $16,66^{\mathrm{ns}}$ & $32,29 *$ & $58,61 * *$ \\
\hline P59 & & & & & & & - & $62,36^{* *}$ & $68,64 * *$ & $59,16^{* *}$ \\
\hline P71 & & & & & & & & - & $28,57^{*}$ & $61,38 * *$ \\
\hline P179 & & & & & & & & & - & $60,49 * *$ \\
\hline \multirow[t]{2}{*}{ P207 } & & & & & & & & & & - \\
\hline & P235 & P239 & P241 & P265 & P276 & P280 & P283 & P284 & P285 & P286 \\
\hline P235 & - & $34,63 *$ & $6,98^{\mathrm{ns}}$ & $38,23 * *$ & $18,97^{*}$ & $35,73 * *$ & $28,62 *$ & $43,93 * *$ & $15,32^{\text {ns }}$ & $22,58^{\mathrm{ns}}$ \\
\hline P239 & & - & $26,85^{*}$ & $76,54 * *$ & $46,67 * *$ & $72,55 * *$ & $14,37^{\mathrm{ns}}$ & $69,79 * *$ & $42,65 * *$ & $39,75^{*}$ \\
\hline P241 & & & - & $37,54 * *$ & $2344 * *$ & $35,80 * *$ & $27,86^{* *}$ & $34,43 *$ & $17,02 * *$ & $26,69 * *$ \\
\hline P265 & & & & - & $52,58 * *$ & $59,60 * *$ & $62,07 * *$ & $84,23 * *$ & $50,56^{* *}$ & $57,42 * *$ \\
\hline P276 & & & & & - & $44,48 * *$ & $42,98 * *$ & $60,88 * *$ & $22,09 *$ & $44,76^{* *}$ \\
\hline P280 & & & & & & - & $61,07 * *$ & $78,32 * *$ & $37,21 * *$ & $52,85 * *$ \\
\hline P283 & & & & & & & - & $60,56 * *$ & $35,99 * *$ & $16,59^{\text {ns }}$ \\
\hline P284 & & & & & & & & - & $52,16^{* *}$ & $53,30 * *$ \\
\hline P285 & & & & & & & & & - & $30,88 * *$ \\
\hline P286 & & & & & & & & & & - \\
\hline
\end{tabular}

*Valores significativos em nível de 5\% de probabilidade; $* *$ valores significativos em nível de $1 \%$ de probabilidade; ${ }^{\text {ns }}$ valores não significativos (*significant values at $5 \%$ probability; $* *$ significant values at $1 \%$ probability; ${ }^{\text {ns }}$ not significant values).

das condições do ambiente. Em cultivo protegido, a taxa de polinização cruzada é praticamente nula, no entanto, pode ser significativa em cultivo a campo aberto (Ribeiro \& Reifschneider, 2008). Nas lavouras de Turuçu, a fecundação cruzada é favorecida pela proximidade entre as plantas, abundante presença de insetos e incidência de vento (Neitzke, 2012), fenômeno que também pode ter ocorrido nas lavouras dos agricultores que doaram as sementes dos acessos que, no dendrograma, ficaram representados em mais de um grupo (P235, P241, P283 e P285).

A distância genética entre os 20 acessos de variedades crioulas de pimentas $C$. baccatum foi estimada a partir de comparações estabelecidas entre cada par de acessos utilizando a AMOVA. Foram evidenciadas diferenças significativas entre 182 das 190 comparações realizadas (Tabela 3). Oito comparações não foram significativas, demonstrando que não foi detectada diferença com o uso de marcadores de microssatélites entre os acessos P08 e P27, P28 e P71, P25 e P285, P235 e P285, P235 e P286, P239 e P283, P235 e P241, e P283 e P286, mostrando que esses pares de acessos compartilham um mesmo pool de alelos. A análise de agrupamento UPGMA reforça esta inferência (Figura 1).

As maiores distâncias genéticas, de acordo com a AMOVA, foram evidenciadas entre os acessos P284 e P27 (80,59\%) e entre P284 e P265 (84,23\%).

Com base na matriz de distância genética entre os pares de genótipos foi construído um dendrograma e foi estimada a distância média geral entre as 100 plantas analisadas. $\mathrm{O}$ valor de 0,69 foi adotado para separação dos grupos formados pela análise de agrupamento. Com base neste valor foram identificados sete grupos distintos (Figura 1). $\mathrm{O}$ coeficiente de correlação cofenética entre o dendrograma e a matriz de distância genética foi elevado, $\mathrm{r}=0,79$. Foi observada $100 \%$ de similaridade apenas entre algumas plantas: P235E e P241D, no grupo 1 e P71A com P28A, B e D no grupo IV. As maiores distâncias genéticas observadas foram entre as plantas P71_C, D, com P25D, grupos 4 e 7 o P25B com P179A, B, C, D, E, grupos 3 e 4, e P59A com P265A, grupo 2 e 4, respectivamente.

Os pares de acessos que não apresentaram significância na AMOVA permaneceram nos mesmos agrupamentos do dendrograma, o que demonstra que esses acessos compartilham o mesmo pool de alelos.

Os grupos formados pelos vinte acessos não tiveram relação com as características morfológicas de fruto. Acessos morfologicamente semelhantes não ficaram no mesmo grupo (como é o caso de P25 e P28), enquanto que alguns grupos reuniram diferentes acessos com 


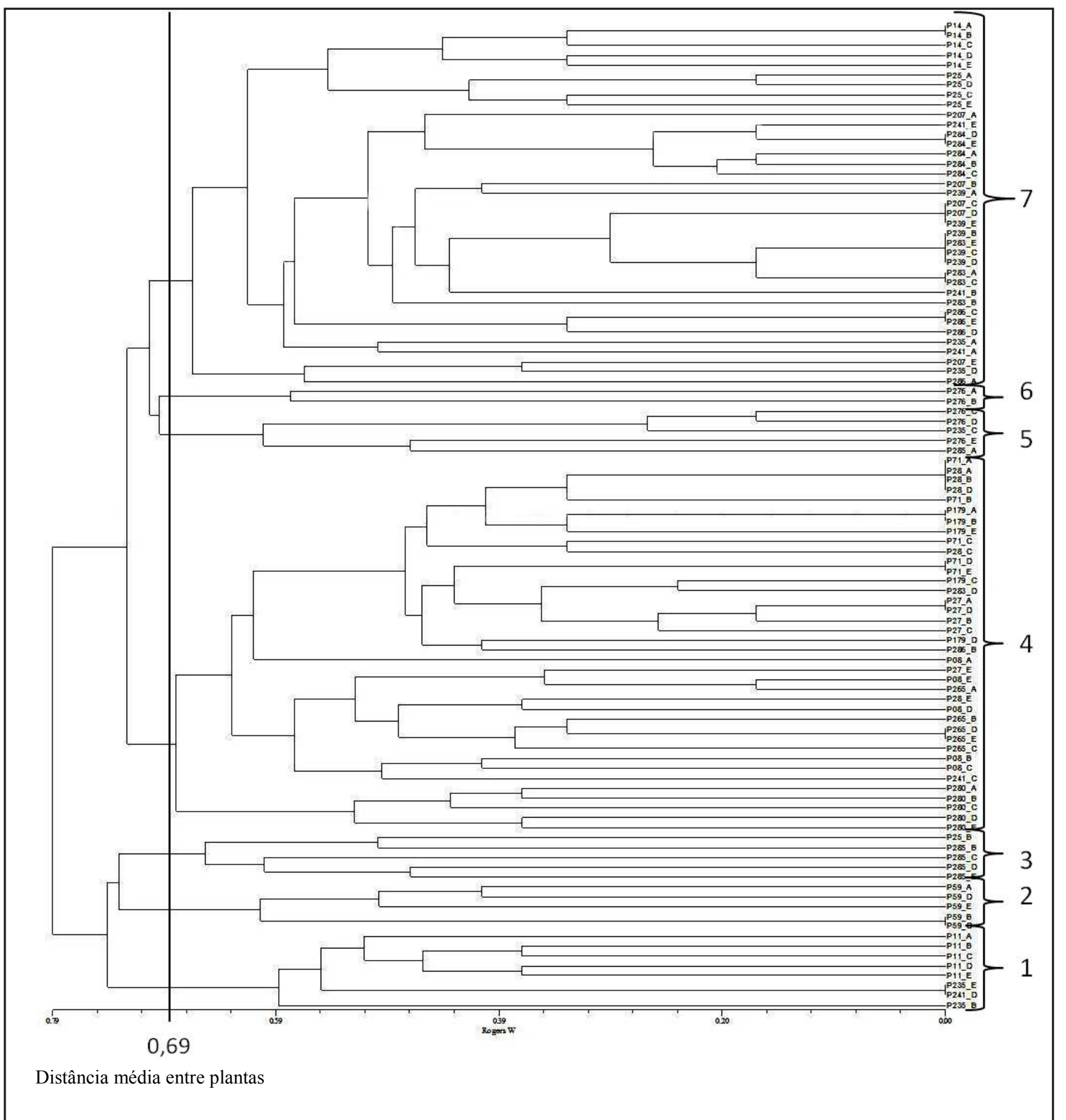

Figura 1. Dendrograma resultante da análise de 20 acessos de variedades crioulas de Capsicum baccatum, obtido pelo método de agrupamento UPGMA, com base na matriz da distância de Rogers modificada (dendrogram from analysis of 20 accessions of landraces of Capsicum baccatum, obtained by clustering UPGMA method, based on the matrix obtained by the Rogers modified distance). Pelotas, Embrapa Clima Temperado, 2012.

frutos bastante distintos (como P28 e P71).

O uso de marcadores moleculares microssatélites permite estimar a variabilidade genética entre e dentro de acessos de variedades crioulas de Capsicum baccatum. A maior proporção da variabilidade genética encontra-se entre as diferentes variedades crioulas, embora também exista variabilidade genética dentro de cada acesso.

\section{REFERÊNCIAS}

ANDREWS A. 1995. Peppers - the domesticated Capsicum. Austin: University of Texas Press.
$186 \mathrm{p}$.

BARBÉ TC; AMARAL JÚNIOR AT; GONÇALVES LSA; RODRIGUES R; SCAPIM CA. 2010. Association between advanced generation and genealogy inbred lines of snap bean by the Ward-Modified Location Model. Euphytica 173: 337-343.

BARBOZA GE; AGRA MF; ROMERO MV; SCALDAFERRO MA; MOSCONE EA. 2011. New endemic species of Capsicum 
(Solanaceae) from the Brazilian Caatinga: Comparison with the Re-Circumscribed $C$. parvifolium. Systematic Botany 36: 768-781.

BUSSAB WO; MIAZAKI ES; ANDRADE DF. 1990. Introdução à análise de agrupamentos. São Paulo: Associação Brasileira de Estatística. $105 \mathrm{p}$.

CLEMENT CR; CRISTO-ARAÚJO M; D'EECKENBRUGGE GC; PEREIRA AA; PICANÇO-RODRIGUES D. 2010. Origin and domestication of native Amazonian crops. Diversity 2: 72-106.

CRUZ CD. 2006. Programa GENES: Biometria. Viçosa: UFV. 382p.

EXCOFFIER L; SMOUSE PE; QUATTRO JM. 1992. Analysis of molecular variance inferred from metric distances among DNA haplotypes: Application to human mitochondrial DNA restriction data. Genetics 131: 479-491.

FERREIRA M; GRATTAPAGLIA D. 1998. Introdução ao uso de marcadores moleculares em análise genética. Brasília: EMBRAPA CENARGEN, 220p.

HANACEK P; VYHNANEK T; ROHRER M; CIESLAROVA J; STAVELIKOVA H. 2009. DNA polymorphism in genetic resources of red pepper using microsatellite markers. Horticultural Science 36: 127-132.

HEISER JRCB. Peppers. 1995. Capsicum (Solanaceae). In: SMARTT J; SIMMONDS NW (eds). Evolution of crop plants. London: Longman, p. 449-451.

LEE JM; NAHM SM; KIM YM; KIM BD. 2004. Characterization and molecular genetic mapping of microsatellite loci in pepper. Theoretical and Applied Genetics 108: 619627.

MOSCONE EA; SCALDAFERRO MA; GRABIELE M; CECCHINI NM; GARCÍA YS; JARRET R; DAVIÑA JR; DUCASSE DA; BARBOZA GE; EHRENDORFER F. 2007. The evolution of chili peppers (Capsicum - Solanaceae): a cytogenetic perspective. Acta Horticulturae 745: 137-169.

MOURA TM; SEBBENN M; CHAVES LJ; GUEDES ASC; OLIVEIRA GCX; KAGEYAMA PY. 2009. Diversidade e estrutura genética espacial em populações fragmentadas de Solanum spp. do Cerrado, estimadas por meio de locos microssatélites. Scientia Forestalis 37: 143-150.

NAGY I; POLLEY A; GANAL M. 1998. Development and characterization of microsatellite in pepper. In: $X^{\text {th }}$ meeting on genetics and breeding of Capsicum and Eggplant. 235-237.

NEITZKE RS. 2012. Recursos genéticos de pimentas do gênero Capsicum - explorando a multiplicidade de usos. Pelotas-RS: Universidade Federal de Pelotas, 117 p. (Tese doutorado).

NEITZKE RS; BARBIERI RL; RODRIGUES WF; CORREA IV; CARVALHO FIF. 2010. Dissimilaridade genética entre acessos de pimenta com potencial ornamental. Horticultura Brasileira 28: 47-53.

OLIVEIRA MVC; BALIZA DP; SOUZA GA; CARVALHO SP; ASSIS LHB. 2012. Caracterização de clones de mandioca utilizando marcadores microssatélites. Revista Ciência Agronômica 43: 170-176.

OLVERA AP; VERDUGO SH; RAMIREZ VR; RODRIGUEZ AG; OYAMA K. 2012 Genetic diversity and structure of pepper (Capsicum anпиит) from Northwestern Mexico analyzed by microsatellite markers. Crop Science 52: 231-241.

OYAMA K; VERDUGO SH, SANCHEZ C; RODRIGUEZ AG; PENA PS; TIZNADO JAG; CASAS A. 2006. Genetic structure of wild and domesticated populations of Capsicum annuum (Solanaceae) from Northwestern Mexico analyzed by RAPDs. Genetic Resources and Crop Evolution 53(3): 553-562.

PATEL AS; SASIDHARAN N; VALA AG; KUMAR V. 2011. Genetic relation in Capsicum annuum L. cultivars through microsatellite markers: SSR and ISSR. Electronic Journal of Plant Breeding 2: 67-76.

PERRY L; DICKAU S; ZARRILLO S; HOLST I; PEARSALL DM; PIPERNO DR; BERMAN MJ; COOKE RG; RADEMAKER K; RANERE AJ; RAYMOND S; SANDWEISS
DH; SCARAMELLI F; TARBLE K; ZEIDLER JA. 2007. Starch fossils and the domestication and dispersal of chili peppers (Capsicum spp. L.) in the Americas. Science 315: 986-988.

POZZOBON MT; SCHIFINO-WITTMAN MT; BIANCHETTI LB. 2006. Chromosome numbers in wild semidomesticated Brazilian Capsicum L. (Solanaceae) species: do $\mathrm{x}=12$ and $\mathrm{x}=13$ represent two evolutionary lines? Botanical Journal of the Linnean Society. 151: 259-269.

RIBEIRO CSC; REIFSCHNEIDER FJB. 2008. Genética e melhoramento. In: RIBEIRO CSC; CARVALHO SIC; HENZ GP; REIFSCHNEIDER FJB. Pimentas Capsicum. Brasília: Embrapa Hortaliças, 55-69 p.

ROHLF FJ. 2000. NTSYS-pc. Numerical taxonomy and multivariate analysis system. Version 2.1. New York: Exeter, Software.

SANTOS AM; DALL'AGNOL M; JANKE A; BORTOLINI F; HUBER KGC. 2011. Análise da diversidade genética de cornichão com o uso de marcadores microssatélites. Revista Brasileira de Zootecnia, 40: 1188-1194.

SOKAL RR; ROHLF FJ. 1962. The comparison of dendrograms by objective methods. Taxon, 11 : 33-40.

SUDRÉ CP; GONÇALVES LSA; RODRIGUES R; AMARAL JUNIOR AT; RIVA-SOUZA EM; BENTO CS. 2010. Genetic variability in domesticated Capsicum spp. as assessed by morphological and agronomic data in mixed statistical analysis. Genetics and Molecular Research 9: 283-294.

WEIR BS. 1996. Genetic data analysis II Methods for discrete population genetic data. 2 ed. Sunderland: Sinauer Associates, 445p.

WRIGHT S 1978. Evolution and genetics of populations - Variability within and among natural populations. Chicago: The University of Chicago. 590p.

XIE WG; ZHANG XQ; CAI HW; LIU W; PENG Y. 2010. Genetic diversity analysis and transferability of cereal EST-SSR markers to orchardgrass (Dactylus glomerata L.), Biochemical Systematics and Ecology, 38: 740-749. 